DOI:

\title{
THE ROLE OF ART IN THE EXPLORATION OF PERSONALITY AS WHOLENESS
}

\section{MĀKSLAS LOMA PERSONĪBAS KĀ VESELUMA IZPĒTĒ}

\author{
Dace Visnola \\ University of Latvia \\ dvisnola@lu.Iv
}

\begin{abstract}
This article describes author's experience of exploring the relationship between wholeness and expressive arts through theory and practice while living half a year in the United States. Through reading, spending time in nature, insight into life situations, looking at and speaking about the arts, and through daily art-making practice, which she experienced as a source of inspiration, a process of individuation and movement toward wholeness unfolded. In this article author analyzes models of wholeness and experiential research on wholeness through the arts. She includes her observations, sensing and feeling the present moment, and provides examples from her dialogue with the arts as well as her own creative expression.
\end{abstract}

Key words: wholeness, individuation, consciousness, unconsciousness, arts, creative expression

Atslēgvārdi: veselums, individuācija, apziṇa, bezapziṇa, māksla, radoša izpausme

\section{Introduction}

The purpose of the article is discussing the nature of wholeness as a human experience through arts and its relevance to individuation, consciousness and unity by addressing several questions and practical examples structured in three chapters. The first chapter comprises several sections and is focusing more on the theoretical basis of wholeness and individuation also including practical experience in expressive arts. First, what is wholeness? What does wholeness consist of and how does it unfold? 
How is wholeness linked with the psyche and the process of individuation? How does creative expression help? And, finally, this chapter describes the Integral Model of Wholeness including author's aesthetic response on the theoretical discussions.

The second chapter describes mandala's healing and the harmonizing role in the individuation process. It includes some examples of mandalas created by author and provides practical examples of creative expression while exploring wholeness.

In the third chapter the focus is on the art (visual, music, dance and performance) created by other professional artists. While experiencing their art and identifying the observer's responses and creative expression, it addresses the following questions: how is wholeness symbolized through arts and creative expression? How do the master pieces of arts help in the exploration process of wholeness? What purpose do the arts serve in this context?

\section{Wholeness and Individuation}

Wholeness is the ultimate goal, "the ideal of human attainment" (Jung 1972b: 12). It is a „dynamic concept of reality, which is the interrelationship of subjectivity and objectivity" (Rudhyar 1983: 139). According to Jung (as discussed by Smith) wholeness has "the potential to endow existence with ultimate meaning and value .. the quest for wholeness can be characterized as a non-transcendent form of psychological ultimacy." (Smith 1990: 3) To define wholeness, it is necessary to find the links to the process of individuation, the psyche, and the structure of wholeness.

Jung described individuation as the process of psychological development and the goal for realization of the Self (Smith 1990: 22), „stimulating creative energies with the goal of transforming the personality" (Brutsche 2011: 19). Individuation can proceed through "the mediation of opposites in the transcendent function, where thinking and feeling, sensation and intuition, and more generally ego and unconscious, enter into creative dialogue" (Kelly 1993: 112). Conversely, James considered individuation as dichotomous to unity; „returning from the solitude of individuation into consciousness of unity with all that is, to kneel down as one that passes away, and to rise up as one imperishable" (James 1902/1929: 386-387). Ferrer pointed out that individuation need not be restricted to „isolated individual inner experiences, visions, intuitions but includes relationships: through intimate dialogue and communication with other beings and the world" (Ferrer, 2002: 191). Author's experience resonates with Jung's and Ferrer's points of view: individuation includes balance in ourselves and accordingly sensitive, supportive and empathetically attuned relationships. 
In the process of individuation the conscious and unconscious are involved; in their relationship they complement each other. The arts serve as a valuable tool for the process of individuation, which leads toward wholeness.

According to Jung consciousness is composed of the sensation, thinking, and feeling functions, as well as intuition (Jung 1964/1970: 49-50). Adding to these four functions there are such archetypes as anima and animus, which remind the ego about the existence of the soul reality and the inner world. Archetypes are Jung's fundamental concept of conscious representations formed in a motif, varying in details but without losing the basic pattern (Jung 1964/1970: 57-58). Anima is the female element in every male, animus the male element in every female (Jung 1964/1970: 17). Adding to these two archetypes, which Jung (as discussed by Chodorow) called the Syzygy, are the Shadow, the Persona, the Self and others. These archetypes are not only concepts but also personifications of different structures and functions of the psyche (Chodorow, 1997: 3). As Brutsche described it, anima and animus ,generate in the individual an awareness of the fact that beyond the outer reality of this concrete world there exists another reality, the absolute spiritual reality of the soul" (Brutsche 2011: 16). The central theme in The Red Book of Jung (2009) is the rediscovery of the soul's own reality that has been lost.

According to Jung's psychoanalytic theory, the unconscious accomplishes its work by the production of fantasies and dream images, which not only balance consciousness but serve as the basis for our conscious experience of reality. The center of consciousness, which experiences the content of the unconscious is known as ego-consciousness. The ego is an „organ of awareness" (Smith 1990: 67) that has evolved out of the unconscious; when fully formed, it possesses a high degree of continuity, organized coherence, and identity.

The Self is the center of the psyche in its totality and the basis of identity. The Self is not an identity that one creates, but rather one's inherent being to be discovered. The Self is "the archetype of unity of the entire psychic system, and, as such, is the expression of one's uniqueness and individuality. The Self in this capacity serves to unify the entire personality - both consciousness and the unconscious - into a coherent whole" (Smith 1990: 68). The Self plays a compensatory role in the psyche to counteract ego imbalances. Accordingly, the ego is subordinate to the Self in the larger framework of the total personality structure. The Self as an archetype of unity and wholeness governs the process of individuation, toward becoming whole realizing one's own inherent being. One of the goals of individuation is to „reestablish the severed link between the ego and the Self; as long as the two are unrelated there cannot be any psychic wholeness or harmony" (Smith 1990: 70-71). 
As one engages in the process of individuation the way is difficult, often „feeling one's own weakness, and having entirely given up own will," feeling „like a man in distress who has no more resources” (James 1902/1929: 394). During the process of individuation "the creative power has also a destructive aspect, not only affirmatively constructive but also negatively destructive" (Brutsche 2011: 20). As a result, some traditional facts, collective values and generally admitted convictions could be annihilated, but at the same time "the destructive aspect of negation inherent to any creativity opens new paths" (Brutsche 2011: 20), as similarly described by Jung (2009) in terms of the inevitability of suffering and pain in the process of liberating the emotions, and uncovering the Self and its inner, symbolically expressed revelations.

\section{Wholeness, Individuation and the Expressive Arts}

Kandinsky described how art is like „spiritual food” (Kandinsky 1912/1977: 7) in difficult periods. The arts allow us to explore all parts of ourselves, our relationships to others, society, and universe; through creative expression, especially when skillfully applied, but also when intuitively and instinctively generated (as is often the case with therapeutic art making), we may transform and refuse old patterns and give birth to our Self. In the process of finding the Self and author's own individuated ways, arts, meditation, and yoga have helped because they facilitated the union of the individual with the divine. As James stated, the mind desires less and is free from "restlessness, objectless and body lesser" (James 1902/1929: 391-392) in creative process. Although desirable, choosing a path toward wholeness makes us vulnerable in ways we would prefer to avoid (Palmer 2004: 9). Thus, both processes of individuation and the way toward wholeness are intrinsically painful; compassionately accepting and becoming aware of the value in the challenges they present on all levels (intrapersonal, interpersonal, and transpersonal) help in keeping us on the path.

\section{A Path Toward Wholeness in Person-Centered Expressive Arts}

According to Natalie Rogers, our path toward wholeness includes the Self, relationship, community, the world, and the universe, which she calls the universal energy source. Rogers's model starts from the inner journey through the expressive arts going into the uncounscious, allowing the inner impulse to come forth, getting insight in this process, and becoming aware of new aspects of the Self, which is placed in the center. Next is the level of relationships, where each person has been heard and is connected with 
another person in an empathetic and supportive environment. Then comes the level of community with collaboration, and the level of being aware of nature, other cultures and connecting to the world at large. The last is the level of universe, in which the main meaning is: „We are all one” (Rogers 1993: 9).

For this development to unfold, empathy, congruence, and unconditional positive regard are needed. In this model witnessing plays a great role. Similarly, Palmer wrote about learning to speak and listen: to speak inner truth, listen receptively to the truth of others, ask honest open questions, offer each other healing, and accepting others as they are; the „soul wants to be seen and heard, and everybody has our inner teacher" (Palmer 2004: 120). The task for expressive arts therapists is to create a space where clients can listen to their inner teacher. It takes time, energy and patience to support clients while they find their own truth, by allowing brief and reflective silence, responding without judgment and commentary, honoring the client subjective experience and heart-felt communication. When we engage with others in such a way, it is our gift to others to be listened to and feel heard.

\section{Stages of Movement toward Wholeness}

When author was looking for practical models of wholeness, Epstein's 12 stages of movement toward wholeness was discovered. It describes a process of searches and psychological development, which usually begins with an unanticipated, challenging event, a major disappointment, dissatisfaction, loss, or trauma. Epstein called the first stage "Suffering," and suggested that the best lesson is to accept the situation and „hear ourselves ask for help" (Epstein 1994: 20).

The second stage, „Polarities and Rhythms”, invites to be aware of the separate rhythms of the parts of the body and join those to larger rhythms in the whole body. For example, while listening to the heartbeat and noticing accelerated rhythm in a stressful situation we are able to slow down breathing. Engaging in this practice of awareness, it was realized that body scanning helped to harmonize whole body rhythm and heartbeat was indeed slower than previously. According to Epstein in a broader sense this stage is connected with the wisdom that organizes the universe into all its rhythms, cycles, and patterns (Epstein 1994: 34-40). The lesson of this stage is to notice and be aware that judgments and polarities tend to manifest themselves in thoughts, and that, actually, we are partially responsible for our distress.

The third stage, „Stuck in a Perspective”, asks to recognize the old way of thinking, seeing and hearing. This refers to the tendency to hold on to 
the familiar and not allow us to move forward (Epstein 1994: 43-58). When developing the capacity to let go, this stage is remarkable for developing a stronger sense of responsibility for our lives, looking for new way of thinking, seeing, and hearing.

In the fourth stage „Reclaiming our Power” we learn to no longer choose to dishonor ourselves, to take power back, and to honor our inner being, which at this point, as mentioned by Epstein, is very important for the commitment to wholeness. It is important to separate ourselves from the previous source of suffering, learn to not judge, and take responsibility of the situation (Epstein 1994: 66-73). In author's practice positive affirmations have been a valuable skill to develop for honoring inner being. The most powerful affirmation has been: I acknowledge myself.

The fifth stage "Merging with illusions” is connected with merging our polarities: light and dark side, goodness and shadow (Epstein 1994: 78-95). When we are in the process of healing, we approach that point when we recognize and integrate opposite aspects of ourselves and move toward wholeness. On author's way toward wholeness she used to make art, visualizing inner polarities. For example, when author worked with her polarities, playfulness and severity, the image of a bird appeared in her notebook (Figure 1A). For harmonizing symbolically two opposite sides or physiologically two hemispheres of brain she used to draw or paint and write with both hands, then move and/or make sounds while feeling my drawings, and writing down experience.

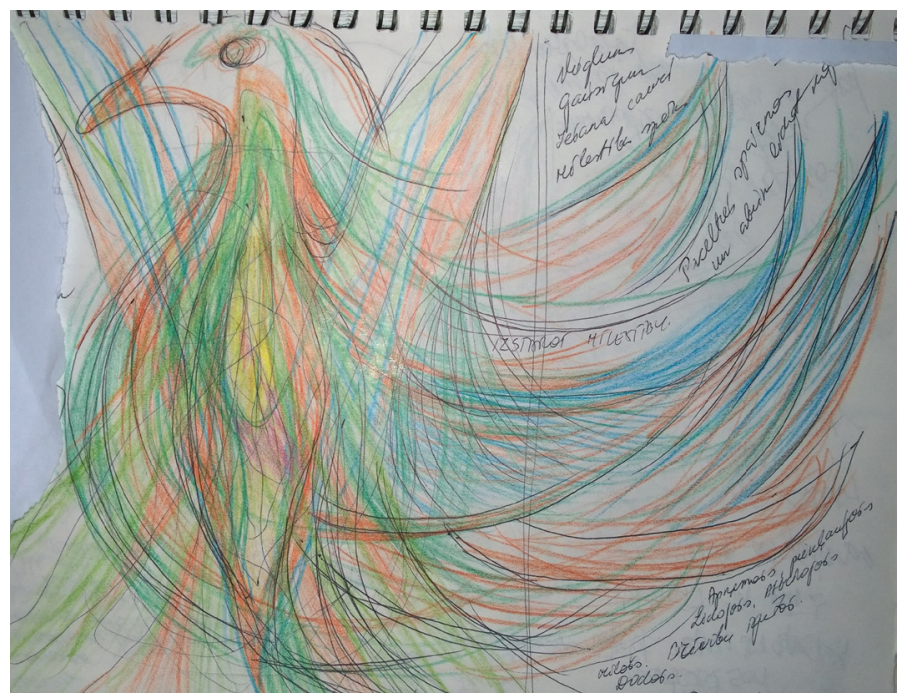

Figure 1A. Bird of inner polarities: playfulness and severity 
The sixth stage "Preparation for resolution" refers to the process of learning to be flexible, following the momentum, and being spontaneous. In this stage some talents begin to appear and we become more energized and more flexible at all levels. Yet, the way to wholeness is not easy. Sometimes the feelings may be uncomfortable (Epstein 1994: 107). For example, while sensing the feelings that cause tension, being spontaneous and following the movements of author's hands resulted with the image of another bird (Figure 1B), which was the image of a resolution of tension.

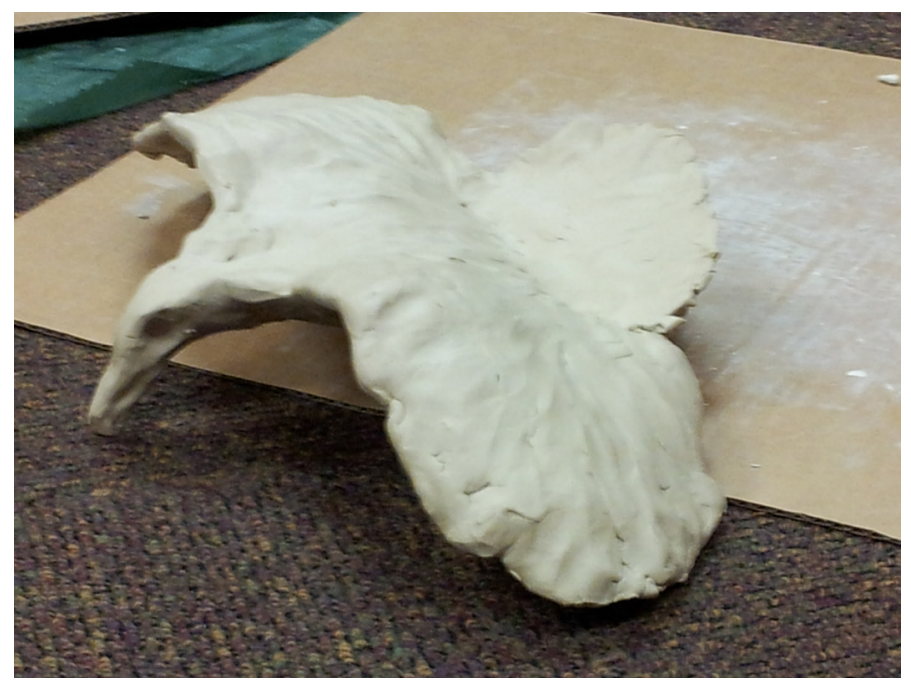

Figure 1B. Bird of spontaneity

If we know that this tension and discomfort are only our lessons, we may be more open to learn that we need to participate in it despite anxiety, fear or discomfort, and that difficult lessons are necessary to achieve further growth into the seventh stage, which is identified as „Resolution." For example, processes of discharging (fever, coughing, sneezing, crying, screaming or laughing), may suggest that we need to empty ourselves for a new state of being, new feelings, thoughts and behaviors, to have new space within us. After discharge we are emptied, and there is a place for possibilities.

In the eighth stage „Emptiness in Connectedness” we can enter into a new stage of gratitude, vulnerability, connection with our rhythms, alignments with events around us. The bird in Figure $1 \mathrm{C}$ reveals the spontaneity of the creative process following author's inner rhythms, elasticity to change decisions and acceptance of the present moment, harmony and openness to new possibilities. 


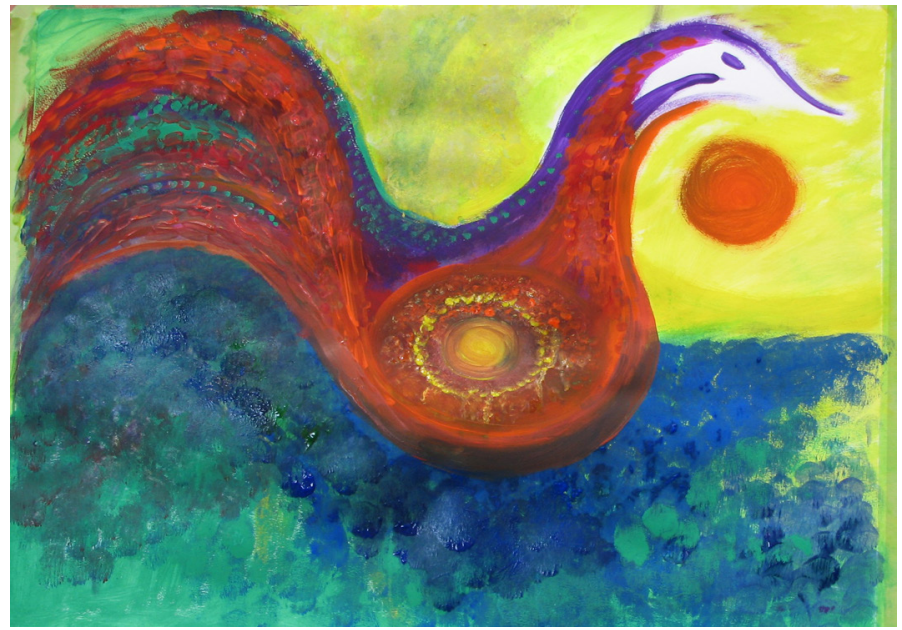

Figure 1C. Bird of inner rhythms

In the ninth stage "Light behind the form" we become aware of our fullness of light and energy, experiencing that we are more than a body, becoming aware of the flow of the life force through and around us. At this stage we feel connectivity with ourselves, others and the universe. This was expressed in the image of yet another bird, which I made in a group process (Figure 1D).

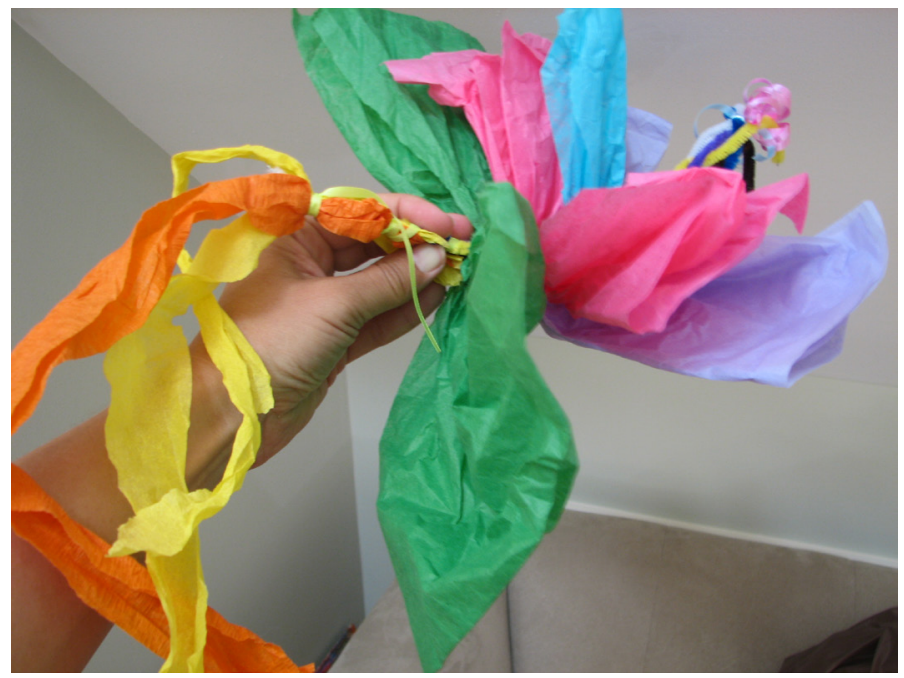

Figure 1D. Bird symbolizing connectivity with ourselves, others, and the universe

We need relationships to find out our true selves. The series of birds (Figures 1A-D) symbolize freedom, author's resolve to take responsibility for her life, an openness to the world and the universe. 
The last three stages in Epstein's model represent a high level of experiencing of wholeness. We experience our awareness of Being, union with the creative power of the Universe (in the tenth stage named „Ascent"); we are renewing beyond our limits, living without being attached to situations and sensing the exact time for entering into the world again („Descent”). In the last stage, „Community," we experience involvement with humanity and recognize that all our choices are spiritual ones, that wholeness brings gifts into community affecting the entire globe (Epstein 1994).

Author's experience shows that the way toward wholeness is the lesson of all life. As life has its ups and downs we periodically could go back, even to the first stage in a given situation-an inevitability of psychological development toward wholeness.

\section{Integral Model of Wholeness}

Ferrer expanded upon the integral Four Quadrant Model developed by Wilber. It is like „reality” (the Cosmos in Wilber's term) in four interrelated dimensions or quadrants: the upper left (the interior of the individual: pretension, subjective experience, intentionality), the upper right (the exterior of the individual: behavior), the lower left (the interior of the collective: cultural world-views), and finally, the lower right (the exterior of the collective: social systems). According to Wilber (as discussed by Ferrer), „all phenomena of existence take part in these four quadrants, that is they have individual (intentional and behavioral) and collective (cultural and social) dimensions, and all types of problems and contradictions emerge whenever we ignore or try to reduce any of them" (Ferrer 2002: 25). According to this, all humans have both individual (intention and behavioral) and collective (cultural and social) dimensions.

In summary, all three models - Rogers's expressive arts, Epstein's 12 stages, and Wilber's integral view of wholeness - show that the path toward wholeness should be focused not only on the self-body, but also on human relationships, communities, world and the universe. Wholeness is connected with grounding and connectivity with everyday life: the social world, relationships and connections, as well as the boundaries and distinction between being one's home and the world. Wholeness includes: inner world and outer world, polarities, connections and new developments.

Author's aesthetic response to all three models is revealed in Figure 2 and is based on Rogers's model. All five levels she perceive as spheres one inside the other. Epstein's 12 stages symbolize a spiral from the center to the outside, which highlight the movement of psychological development, and flow through all levels on different planes and directions, touching 
the four quadrants of Wilber's model. I have named this image „All is connected." On our way toward wholeness we go through all five levels, 12 stages, and individual and collective dimensions.

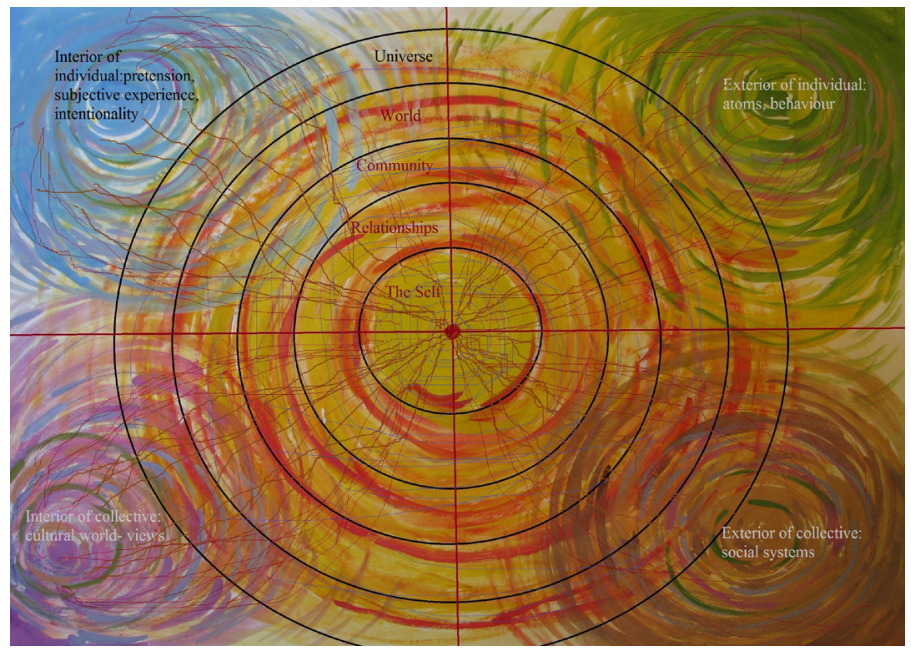

Figure 2. All is connected

Wholeness is a dynamic concept; Rudhyar characterized the movement of wholeness as „centripetal, sometimes centrifugal. The pulsation from center to circumference and back to center is like the heartbeat of being or wholeness" (Rudhyar 1983: 72). This corresponds to author's aesthetic response visualizing Epstein's model of 12 stages as spirals in Figure 2. While analyzing these models author realized that the process of the formation of the Self is only a circumambulation and not linear; similarly the evolution of our way toward wholeness is multifaceted and spherical. In all four corners circles are painted in order to reveal the spherical structure.

The integral Four Quadrant Model is reminiscent of Jung's concept of the psyche. There are four quadrants in a mandala, which according to Jung, is the "psychological expression of the totality of the Self" (Jung 1972a: 72), and „goal of psychic development is the Self” (Jung 1972a: p. v.). The totality includes personal consciousness and unconscious, as well as collective unconscious, which are common to all mankind. Jung's paintings of mandalas in The Red Book (Jung 2009; 2009/2013) bring together the inner world, the personal, including consciousness and unconsciousness, and expands it to reach another dimension - the collective - including consciousness and unconscious. While thinking about the symbolic meaning and visualized the structure of Jung's concept of psyche author realized that inclusion of these four dimensions is necessary 
in her aesthetic response to models of movement toward wholeness (Figure 2). Similarly the mandala has four quadrants and tends to be threedimensional as well. It is considered to be a symbol of individuation and wholeness.

\section{The Mandalas Symbolic Expression of Individuation and Wholeness}

In The Red Book of Jung (2009), as discussed by Brutsche the images of the individuation process of finding the Self are the egg, the mandala and the polarities: male and female, child and adult, as well as potentialities of self-development: stable and ever-changing, simple and multiple, inner and outer, spiritual and emotional, filled with passions (Brutsche 2011: 18). In the mandala ornaments of the inner circle pour out and receive something from outside, which symbolically means „projections stream back 'inside' and are integrated into the personality again" (Brutsche 2011: 15).
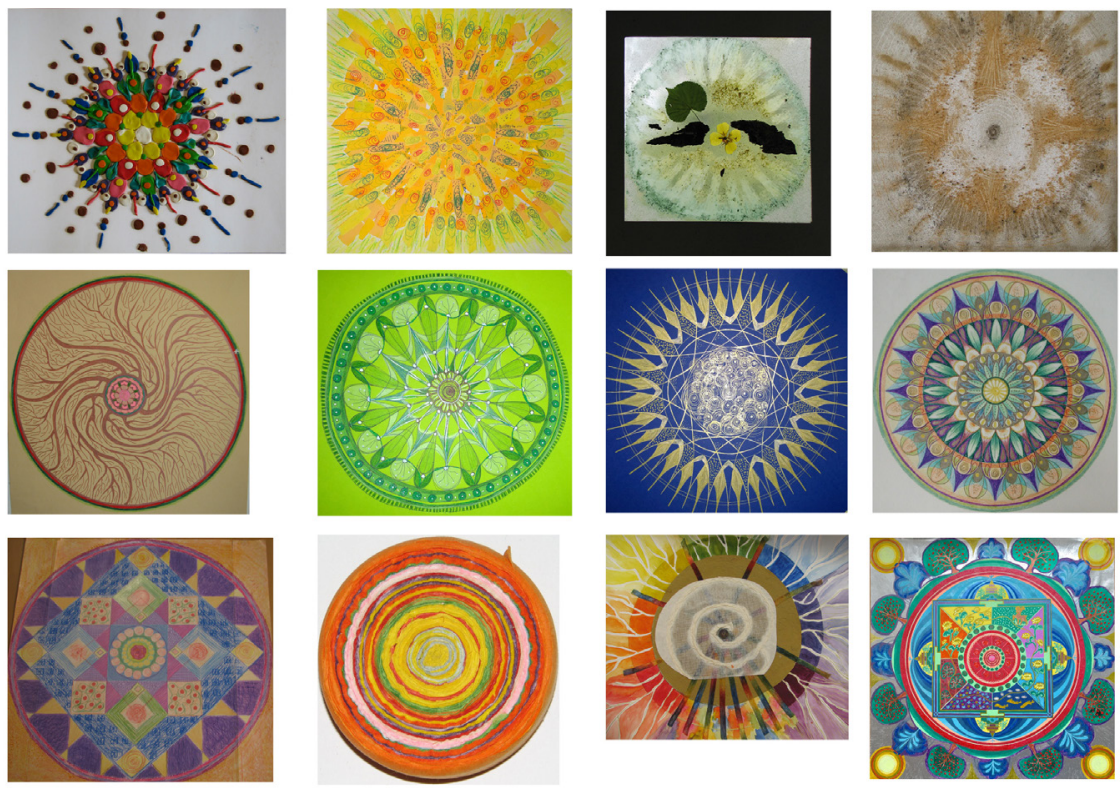

Figure 3. Examples of mandalas

Usually a mandala contains three circles, symbolically intending to „shut out the outside and hold the inside together" (Jung 1972a: 72). The „squaring of the circle is one of the many archetypal motifs of our dreams and fantasies, and it could even be called the archetype of wholeness" (Jung 1972a: 4). The mandala is the „whole being, the monad, which corresponds 
to the microcosmic nature of psyche, the wholeness of personality." In the Sanskrit mandala means a circle. Jung noticed that mandalas usually appear in situations of psychic confusion and distraction (Jung 1972a: p. v). A mandala corresponds to the inner situation of the moment. When mandalas are made spontaneously for overcoming anxiety and harmonizing and/or drawn spontaneously for overcoming chaotic state they release tense feelings. After acting them out the mandala's structure contributes to healing (see Figure 3 - examples of author's healing mandalas).

Usually a mandala has a center and protective circle but sometimes we can see the process of looking for the center. A mandala consists of four parts and includes four functions of consciousness: sensation, feeling, thinking and intuition (Jung 1972a: 51). Wholeness is attained when all four aspects are in balance and in perfect union. The mandala is „superimposed on the psychic chaos so that each content falls into place and the weltering confusion is held together by the protective circle" (Jung 1972a: p. vi). The mandalas in the first row of Figure 3 correspond to the first three stages of Epstein's model.

Although coloring mandalas is a harmonizing tool and has a healing effect, it is most effective to draw a mandala spontaneously without thinking, only following to the movements of hand as drawn mandala. As Jung said, „Nothing can be expected from an artificial repetition or a deliberate imitation of such images" (Jung 1972a: 5) because it is authentic symbols, colors and meanings of the forms drawn in the mandala that facilitate individual healing and transformation. For example, the mandala drawn with gold on the indigo paper, in the second row of Figure 3, symbolizes transformation. Drawing mandalas facilitates „formation, transformation, eternal mind's eternal recreation" (Jung 1972a: p. v). Looking at the drawn mandalas, it is possible to observe psychic transformations (see Kellogg 1978, for a discussion regarding 13 stages of observing psychological development in therapeutic mandala making).

Jung has observed that all the paths he had been following, all the steps he had taken, are leading back to a single middle point, to the center. Therefore, he concluded that the mandala is the „center, the path to the center, to individuation" (Jung 1972a: p. v). In the process of individuation finding the Self means focusing on the center and concentrating. For example, patience and concentration are necessary for creating a mandala from long colored paper strips rolled into a spiral (second from the left side in the bottom row of Figure 3).

The center of a mandala symbolizes innermost, central point within the psyche, to which „everything is related, by which everything is arranged, and which is itself a source of energy" (Jung 1972a: 73). The energy of the central point urges one to become what one is. The center is not felt or 
thought of as the ego but is expressed as the Self. According to Jung, „the ego is the expression of individual existence" (Jung 1972a: 74); it tends to cause unpleasant emotions and conflicts in life. Mandalas help to overcome chaotic and disordered states marked by conflict and anxiety. For example, in the lower left corner of Figure 3 is a mandala, which was drawn on a large piece of paper (39.5 in. square) to act out anger and disappointment, helping overcome conflict and anxiety. When the mandala was finished, it was not liked by author because it was linked with the concrete situation. Only after two days of creating this mandala the Latvian sign of the morning star "Auseklis" (in Latvian) with a very powerful meaning was noticed. Now the same mandala looks harmonious. This shows that the mandala is a very powerful tool in art therapy, and if the situation is resolved we then accept our mandalas as authentic reflection of the Self.

The object of a mandala is "the Self in contradistinction to the ego, which is only the point of reference for consciousness, whereas the Self comprises the totality of the psyche altogether, i.e., conscious and unconscious" (Jung 1972a: 5). If the Self is a goal of psychological development, then the Self, if visually symbolized, could be seen as the center of wholeness, which is indicative of a nonlinear process of individuation and spiritual development. Mandalas display light and dark sides and align the irreconcilable opposites represented by typical symbols of the artist under certain circumstances thus providing a considerable therapeutic effect while bridging seemingly hopeless splits. For example, the mandala in the bottom row of Figure 3, third from the left, put together opposites (light/dark, warm/cold colors, opposite colors of the wheel of colors) and by integrating them, display the process of individuation.

According to Jung, the recognition of the bipolarity of human nature and of the necessity of conflicting pairs of opposites is essential. He mentioned that "after the symbols of madness experienced during the period of disintegration there follow images which represent the coming together of the opposites: light/dark, above/below, white/black, male/ female" (Jung 1972a: 140). Thus, images of polarities in art could be a sign of integration on the path toward wholeness. Figure 4 is an example of how the periphery of the mandala's center is surrounded by symbols of the paired opposites, which belong to the Self and make up the total personality. This mandala includes symbols of cultural values, which show a more integrated personality than in previous mandalas.

According to Jung, a „certain number of these, however, are permanently or temporarily included within the scope of the personality and, through this contact, acquire an individual stamp as the shadow, anima, and animus. The Self, though on the one hand simple, is on the other hand a composite „conglomerate soul” ((Jung 1972a: 73). Mandalas drawn in 
the individuation process include a limitless wealth of motifs and symbolic allusions, which express the totality of the inner and outer experience of the world or is an essential point of reference. For example, the mandala drawn by colored pens (20 in. square), first on the right, on the bottom row of Figure 3, expresses author's process of individuation, striving toward wholeness. The drawing process and the story embedded into this mandala include symbols of the Self, relationships, community, world and even universe.

The stories that informed the mandalas shown on the second and third lines of Figure 3 and the mandala in Figure 4 correspond to stages 4-9 of Epstein's model. These images show the dynamics of the process toward wholeness. According to author's experience, while creating mandalas (and while leading mandala groups for adults from 2011), creating and even dancing of mandalas facilitate a sense of stability, as inner peace gradually returns. The Mandala helps in centering and aligning with the union of all opposites according to the universal rules.

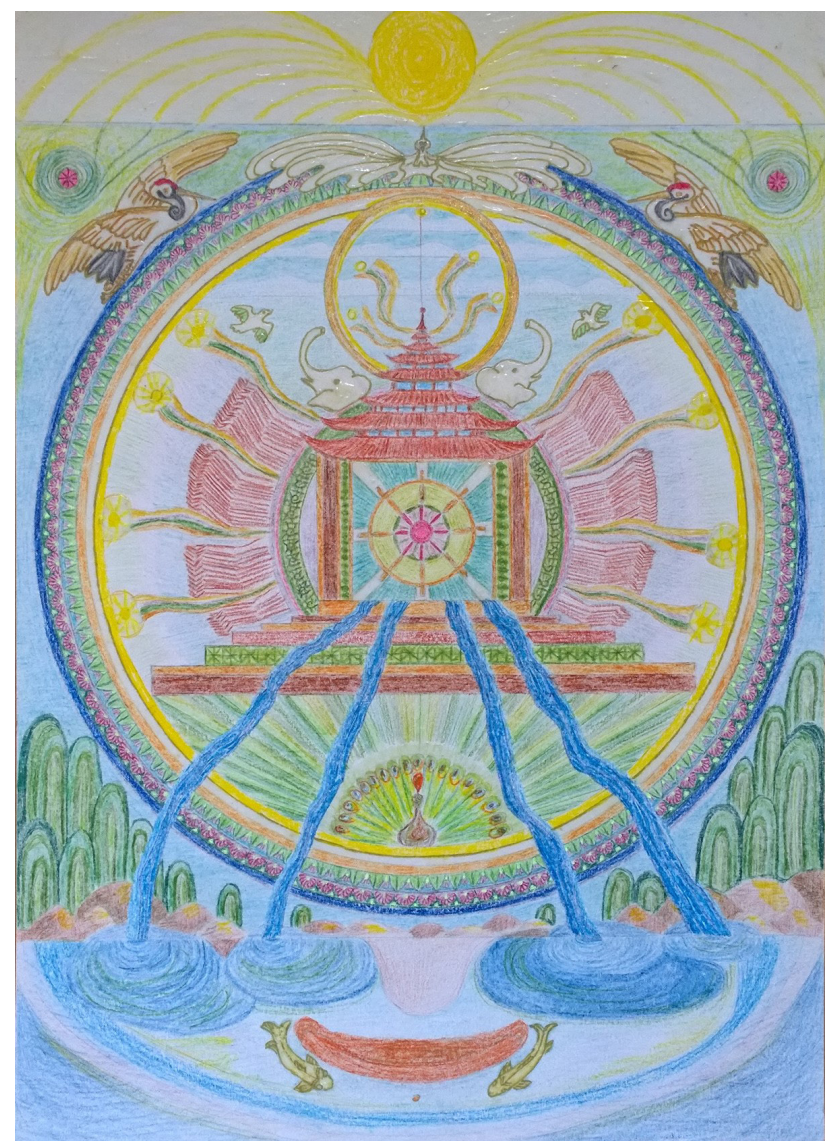

Figure 4. My way 
However, a mandala is also a symbol of the individuation process, while finding the Self, although it includes the „microcosmic enclosed within the macrocosmic system of opposites" (Jung 1972a: ix). Wholeness is harmonious if all is linked together in balance.

\section{Wholeness in the Arts and the Audience's Creative Perception}

In this chapter are explored accomplished artists' works, which had inspired on the path toward wholeness while being in the United States. It was a phenomenological research of wholeness. The psychological significance of the expressive arts and the audience's creative perception in response to the arts are highlighted, as it pertains to Rogers' (1993) levels on the path toward wholeness: self, relationships, community, world, and universal unity in examples from music, performance, dance and authentic movement, and the visual arts. While exploring wholeness through the arts, author's exploration not only included a review of the literature but also her response through feeling and sensing, observing different modalities of the arts, thinking and intuiting others' work, and creating author's own art.

\section{Music and Silence}

According to the models of wholeness, we begin with ourselves. For author's inner journey toward wholeness the most important was John Cage's „4.33” (Cage, 1952/2010), an invitation to be silent for 4.33 minutes. In the process of experiencing the music of silence for 4.33 minutes author realized the necessity to explore wholeness in an experiential way by listening, sensing and feeling, drawing, movement and writing. Listening to the silence 4.33 minutes every day for a week were like meditation. At the same time some feelings emerged, some ideas and thoughts were written in the notebook. The notes were an aesthetic response to more or less silence in mind and nature. Words, such as freedom, strength, and centeredness, intuition and senses of body, feelings and emotions emerged while being silent. These notes included also polarities: harmony and disharmony. Cage has mentioned that „disharmony is simply harmony we are unaccustomed to" (Cage 1988: 2). It was taken to mean acceptance of what is coming up without prejudice and was realized that by sensing of body and noticeing what is going around makes posibility to feel like being as a part of the universe on the way towards wholeness.

Nowadays Mark Applebaum's way of composing music is similar to Cage's masterpieces. Applebaum has exhibited 12 large sheets of paper filled with forms (lines, circles, squares) in the Cantor Arts Center, Stanford, in 2010 (filmed by Arnold, 2010). Each day musicians performed music 
according to Applebaum's drawings. Cage has preceded Applebaum. The poetry of Cage (as discussed by Dür, 2003: 13-25) could have likely been played by these musicians as well. Both Cage and Applebaum have left "the puzzle unfinished" (Cage 1988: 2). According to Cage, „art is not an escape from life, but rather an introduction to it" (Cage 1988: 1). Music help us, as listeners of sound and silence, to develop awareness, become more open, understand ourselves and our relationships with others in the world; listening to sound and silence grows our intuition, as we develop toward experiencing wholeness and becoming whole.

\section{Performance}

Several performances of Marina Abramović and interviews with her (Abramović 2012, 2013a, 2013b) show Abramović's story and motion toward wholeness while comparing her earlier art performances with a lot of prompts to later ones, for example, performance "Artist is Present" when she did not need any prompt and made only direct eye contact with people. As eyes are like mirrors of our souls, then exposing our soul is beyond being physically naked. Opened eyes - direct eye contact - is like opening one's souls to others.

As Abramović also mentioned in her interview, „artists cannot live without breathing. Art is the way of breathing" (Abramović 2013a). Metaphorically breathing symbolizes life. Breathing had a role in the movement toward wholeness as it is a tool for balancing ourselves. Mindful breathing balances us in the center where „conscious and unconscious minds meet, where inner and outer worlds join, where sense of the Self encounters boundless Universal Self" (Levey \& Levey, 1998, p. 56). Wholeness begins from the inside out. Breathing in and out with full awareness is the first possible movement toward harmony and balance. Mindfulness of breathing and body is the starting point toward wholeness.

Art making helps us to come back to our authenticity. In everyday life we used to „project our inner darkness on others, making 'enemies' of them and making the world a more dangerous place. Our inauthenticity and projections make real relationships impossible, leading to loneliness" (Palmer 2004: 16). This is not the same as being alone. If we are alone with our inner teacher we can find our own way. Understanding our shadow side enables us to realize our own reality, and therefore we take a step toward wholeness. Art is mental work and motion toward the wholeness of artists and spectators, and for both (as mentioned in a video interview of Abramović 2013) it is like "cleaning the house from inside, cleaning the body" and mind. Mindfulness entails our awareness of sensing, feeling, thinking, intuiting and being, intensions and action in the present 
moment (Levey \& Levey 1998: 64-67). While creating art, artists use their sensitivity, feelings and emotions.

Performances let us think about the lessons of flexibility and nonattachment. As Abramović mentioned, if „we have to fix things and things have to be in a certain way, then you don't see the flow, you don't see how the whole energy goes ... and how things are actually unpredictable" (Abramović 2006: 32-34). The meaning is about being flexible to change plans according to our intuitions and situation if necessary; about being ready to leave past behind.

The other lesson is about being present. The environment for the performance is created before, but the performance is an unexpected process from beginning to end. It is like our life movement toward unknown relationships and situations. Marina Abramović's art is about being in the present moment, about the unity of the body and mind, about consciousness and unconsciousness, about visible and invisible worlds. It seems to be her path toward wholeness and is, at any rate, an inspiration for the viewer to internalize the embodiment of this developmental process (whether consciously or unconsciously).

The path toward wholeness includes close relationships. For example, such relationships with feelings and emotions are shown from the earlier performances to the last one "The Lovers" performed by Abramović and Ulay (Abramović 2012, 2013b): getting together, aloneness and togetherness, openness and playfulness, shared awareness and divorce the authenticity of the emotions, feelings, and vulnerability in breaking up a relationship are inseparable from the experience of love.

Furthermore, the path toward wholeness includes social relationships. For example, Yoko Ono's performance „Cut peace” (Yoko Ono 1965) led me to think that it is not only concentration of the artist herself, but also feeling and sensing reaction from the audience: their silence, internal feelings and inner being, sensing the body, which, according to Ono (as cited by Chung) is "the scar of our mind” (Chung 2011: 309). It could be a way to becoming aware of the unity of the mind, body, soul, and emotions, which is an important part of experiencing wholeness.

To experience wholeness, we concentrate not only on ourselves but also on the community, taking into consideration their feelings, emotions and reactions. I think this is the case when we invariably witness „liberation from self-imposed suffering, an opening of the heart, and a commitment to a compassionate and selfless life" (Ferrer 2002: 145). Ono's Cut Peace performance was a provocation of intervention in order "to shake out of habitual ways of thinking" (Chung 2011: 306). This is one example of how performance influences our lives, encouraging us to look differently at our lives, as it alters the ways we look at ourselves, others, the community, and the world. 


\section{Body Awareness, Narrative, Dance, and Authentic Movement}

Social relationships are also depicted in the Buck Dance (Lemon \& Gonnerman 2009: 8.22'-11') and storytelling through movement (Lemon 2011). In the Buck Dance, dancers tell the story of the historical event of the Freedom Bus riders (Lemon \& Gonnerman 2009: 41.24'-45.24'), which happened in 1961 (Profeta 2011). Lemon's storytelling through the movements is reminiscent of Olivia Corscon's Body Tales (Corson 2010), which is a "creative and healing practice that integrates movement, voice and personal storytelling. This unique form combines elements of dance, theater and expressive arts, and encourages and supports an embodied value system in which the well-being of the Earth is central" (Corson 2014). Compared with Corson's body tales, Lemon's dances are mostly without words but with many social metaphors.

In storytelling, for example, Come Home, Charlie Patton (Lemon \& Gonnerman 2009: 50.27'-52.24') Lemon explored past events. Even if he did not know the original event, he tried through his body to imagine how it could be and how people would feel in the concrete past situation. From this point of view, the value of Ralph Lemon's dance performances is the embodiment of situation, paying attention to the events and more or less healing ancestral wounds. Lemon's performances reminded me of Armand Volkas's (2014) Playback Theatre, which tells the stories of immigrants, and the workshop Healing the Wounds of History, which is about psychotherapeutic work in groups for healing collective trauma, intercultural conflict resolution, and peacebuilding. Compared with Volkas's work, Lemon's dance performances and storytelling are more akin to artwork that encourages audiences to think about past events. Still, the question remains - to what degree dance performances center around the dancer's self, and how much do they lead to selfless awareness and inspire action in the world?

In the videos of Ralph Lemon's dance performances (Lemon \& Bither 2010; Lemon 2011) and in the interview the dancer spoke about several bodies: chemical (molecular, cellular), thinking (,sense of what body is already doing and has done"), spiritual (sense of something „beyond the words and cognitive experience") and transcending (transformation of the body during the life) (Lemon \& Gonnerman 2009: 3-5), which correspond to the steps toward wholeness through listening to our body and its awareness in the present moment. In the Lemon's story about Walter's dancing (Lemon \& Gonnerman 2009: 52.44'-55'), because Walter's moves rely on embodied memory of his past dance steps, there is a link between the authentic movement of finding out how the body wants to move and letting it move in the present moment. Witnessing authentic movement and the narratives 
it delivers, inspires transformation through bodies, minds and emotions, first in the performers, then in the audience. Such experiences facilitate for the performer and audience movement on the path toward wholeness till the level of the world, as they encourage, through freedom of expression and response, a non-judgmental view of the self, and acceptance of the authenticity it communicates.

\section{Visual Arts}

The individual's conscious attitude is one-sided. Behind consciousness there lies the unconscious psyche, which affects consciousness „from behind and from inside, just as much as the outer world affects it from in front and from outside" (Jung 1972b: 136). The inside experience is valuable in taking into consideration all five senses while orientating toward the outer world. The collective unconscious shows „no tendency to become conscious under normal conditions, nor can it be brought back to recollection by any analytical technique, since it was never repressed or forgotten" (Jung 1972b: 80). By activating all the senses and feelings through creative expression, we may identify and recognize unconscious material and make it conscious. Art is helpful for recognizing the unconscious world, making its contents accessible and understandable, and in such way preventing a dangerous splitting of the unconscious processes from consciousness. At the same time it is necessary to take into account that in the contrast of objective conscious representation, art and the art making process are symbolic.

We are more or less conscious about everyday life situations, but we still have the unconscious. For example, there is a connectivity between the conscious and the unconscious in Marcel Duchamp's „Fountain” (Duchamp 1917, 1964). It reminds of the unconscious because it seems to be something that we deny. This artwork is a story of accepting two sides: light and dark, two polarities or dualities. When we look more precisely at this artwork from different points of view, we can notice the symbolic presence of male and female, and some more polarities. Molesworth discussed the constructs of private and public, ambition and laziness in the context of the artist's ability to make art. Duchamp's art encourages us to pull down the boundaries and play, which is „a dimension of freedom, a self-distraction, relaxing oneself, forgetting oneself and recuperating oneself" (Molesworth 1998: 56). It is another way toward wholeness using a provocative play asking for elasticity and calling for noticing the momentum when the circumstances are different from before; encouraging stopping, moving, and working, inviting to notice the presence. This approach encourages being present, tolerating differences, and accepting the dark side integrating it with light. 
Similarly, we can find connection even with the world and universal in Pablo Picasso's „Guernica” (Picasso 1937) which is, according to the painter's words, an allegory of the bombing on Guernica in 1937, and which is described as "an unforgettable image of violence and terror" (Davenport 1996: 181). There are many discussions about this masterpiece. This painting may also be considered as an expression of the psychological model of creation, collective consciousness and unconscious. „Guernica” is reminiscent of the shadow or uncanny recesses of the mind (individually and collectively). Picasso used mythological images and the painting bears its own meaning intended by the artist. At the same time without knowing the meaning viewers can develop their own interpretation according to their life situations. In art therapy, we can work with feelings and emotions evoked by well-known art, especially if the viewer is not familiar with the history of the piece. Each artwork is the artist's way toward wholeness. When we are looking at, thinking and speaking about others' art, the viewing, interpretation, and integration of the art becomes our way toward wholeness.

The masterpieces of art analyzed in this chapter are just as examples. Each media of art (visual, music, dance, performance etc.) is able to help to reach all five levels on the path toward wholeness while exploring wholeness through the arts.

\section{Creative Perception of Art}

One of the effects of engaging a creative process of becoming an active perceiver of the great arts lies in the unconscious activation of archetypal image. By giving a personalized shape to, and elaborating on these images the language of the creator or perceiver's unconscious becomes visible and sometimes even understandable. Only when the unconscious is turned to the visionary mode do we begin to ask questions. Artists help us to understand the reactions we have to the images that emerge from the unconscious. Artists intuitively and/or intentionally translate collective unconscious archetypes into the language of the present, and in such a way help us find out not only the way back to the Self but also to represent „a process of self-regulation in the life of nations and epochs" (Jung 1972b: 83).

While looking at art for the purpose of wholeness development, the meaning of the artwork as intended by the artist is not essential; the most important thing is to notice our feelings and memories: are we astonished, confused or bewildered? Are we asking for explanations or commentaries? Does it remind us of something in our everyday life? Or maybe it reminds us of our dreams and night fears? Do we notice our resentment when we are viewing art? Do we reject the artwork, and if so why? Do we not want to speak about it, and if so why not? 
There are emotions that the artist has, and then there are emotions that we have while we are looking at the masterpiece. The art, details of the masterpiece of art, could be a source for finding the unconscious in ourselves. Observing art in this manner could be instrumental to support the individuation process and could be helpful for finding new possibilities and even our way in life appreciating everything that is in us: positive features and shadows, strengths and weaknesses, joyfulness and sadness.

It is commonly accepted in the field of art therapy and the expressive arts that everybody can create art (Rogers 1993: 7; Rubin 2005: 20-23). Our own art or looking at others' art is a source for self-reflection. Even though the art is abstract, we can project our own story upon it. It could be a story of relationships, of one's everyday life and the world processes. Each of us can derive from artworks personally significant meaning at any given moment. The deepest engagement with the arts, especially abstract, requires silence, focusing attention and thus, clearing our minds. It is like a meditation in trusting our own experience. While looking at art we can ask questions such as: What are these images about for me, and what do they tell me? What is essential for me in these images to understand the world right now? Could these images represent some parts of my life? There is „the internal truth, which only art can divine, which only art can express by those means of expression” (Kandinsky 1977 [1912]: 9) but „complete understanding of reality and human nature needs to include spiritual insights and perspectives" (Kandinsky 1977 [1912]: 1).

The artist expresses him/herself but also undertakes the task of expressing the collective unconscious. The artist „must have something to say, for mastery over form is not his goal but rather the adapting of form to its inner meaning" (Kandinsky 1977 [1912]: 54). Accordingly, the artist must link together the universal and the particular in nature through an aesthetic form. If we live according to universal rules of appreciating nature, if we look through the universal view of reverence for life, we are able to develop art, which is filled with the power of the universe and unconditional love. Art is beautiful in that it is made by the soul and generated by the inner need to create art. From this perspective, art provides us with a more particular as well as universal understanding of ourselves, others and relationships, the world and the universe. In that sense, art brings us closer to wholeness.

\section{Conclusion}

Wholeness includes the Self, relationships, the community, the world and the universe. Wholeness is closely linked with the process of individuation. 
It brings together polarities, the inside and the outside, a microcosmos and a macrocosmos.

In this article author has analyzed three models: Rogers's model of the path toward wholeness using a person-centered expressive arts approach; Epstein's model of 12 stages of movement toward wholeness; and Wilber's integral four quadrant model. The analysis include Jung's concept of psyche, which includes personal (consciousness and unconsciosness) and collective (consciousness and unconsciosness). To summarize the analysis author has created an aesthetic response with a vizualized stucture of movement toward wholeness, which included five spheres of levels - the Self in the center, relationships, community, the world, and the universe, spiral of twelve stages and four quadrants with individual and collective dimension, including Jung's concept of conscious and unconscious of psyche. Accordingly, wholeness is not only linked with spirituality but also with grounding and connectivity with the social world, relationships within one's inner world and outer world, boundaries and new development.

The symbol of the way toward wholeness is the three dimentional sphere. The symbol of individuation is a mandala. The center of the mandala is the Self, which is the goal of psychological development. Author has revealed the dynamics of her way toward wholeness using the images of mandalas taking into consideration Jung's concept and comparing the development of images of mandalas with Epstein's model of stages.

In the last section author has analyzed other artists' masterpieces of art according to Roger's five levels of the path toward wholeness. Being silent, noticing processes around, listening music of nature and urban environment, process of psychological development, as well body awareness, expressive and authentic movement coresspond to the first level: The Self and to the second level: Relationships. Performances address three levels - The Self, Relationships and Community. Adding to those three levels, narrative and expressive movement (storytelling, body tales, playback theatre) correspond with the fourth level: processes of the world. Visual arts and creative perception of art provide universal understanding of overselves and relationships with others, social connections in community, world processes and universal regularities.

In all these modalities of creative expression, the experiences of the artist, the viewer, and the witness who chooses to respond to the art through creative expression are both distinct and interelated. The artist creates with the audience in mind, while the audience is given the freedom to respond, by projection and independent meaning-making through all the senses, the intellect, and the intuition. Such active, receptive, and creative relationship with the arts is a valuable and powerful tool within the individuation process toward wholeness. 


\section{REFERENCES}

Abramović 2006

Abramović 2012

Abramović 2013

Abramović, Ulay 2013

Brutsche 2011

Cage 1988

Cage 2010

Chung 2011

Chodorow 1997

Corson 2014

Corson 2010

Davenport 1996

Duchamp 1917, 1964

Dür 2003

Epstein, Altman 1994

Ferrer, 2002

James 1929

Jung 1970

Jung 1972a
Abramović, M. (2006) Interview with Ch.Thomson \& K.Weslien. Pure Raw: Performance, Pedagogy, and (Re)presentation. Performing Arts Journal, 82, pp. 29-50.

Abramović, M. (2012). Artist is present. Trailer. [Video file]. Retrieved from https://www.youtube.com/watch?v $=$ YcmcEZxdlv4 [Viewed: 27.05.2014.]

Abramović, M. (2013). Advice to the young. [Video file]. Retrieved from http://www.youtube.com/watch?v $=8 \mathrm{Ck} 2 \mathrm{q} 3 \mathrm{YgRlY}$ [Viewed: 27.05.2014.]

Abramović, M., \& Ulay. (2013). The time: Marina Abramović and Ulay [Video file]. Retrieved from http://www.youtube.com/ watch?v = gOYIcozkvA0 [Viewed: 27.05.2014.]

Brutsche, P. (2011) The Red Book in the context of Jung's paintings. Jung Journal: Culture \& Psyche, 5(3), pp. 8-24.

Cage, J. (1988) Tokyo lecture and three mesostics. Perspectives of New Music. 26(1), pp. 6-25.

Cage, J. (2010). 4.33' [Video file]. Retrieved from https://www. youtube.com/watch? $\mathrm{v}=$ JTEFKFiXSx4. (Original performed 1952). [Viewed: 05.01.2015]

Chung, Y. (2011) Yoko Ono's 'Cut Piece' as a Participation Work. International Journal of Arts in Society, 5/5, pp. 303-313.

Chodorow, J. (Ed.). (1997) Encountering Jung: Jung on active imagination. Princeton: Princeton University Press.

Corson, O. (2014). Body tales. [Internet resource]. Retrieved from http://www.bodytales.com/.[Viewed: 10.01.2015]

Corson, O. (2010). Body tales improvisation. [Video file]. Retrieved from https://www.youtube.com/watch?v=yROoijKIPVE. [Viewed: 10.01.2015]

Davenport, G. (1996) Guernica. The Hunter Gracchus: And Other Papers on Literature and Art Washington D.C.: Counterpoint, pp. 180-186.

Duchamp, M. (1917, 1964). Fountain. [Video file]. Retrieved from https://www.youtube.com/watch?v = FmjSUyyc-3M [Viewed: 05.01.2015]

Dür J. (2003). Glasswanderers. The Marcel Duchamp Studies Online Journal, 2/5, pp. 1-56. from www.toutfait.com [Viewed: 05.06.2014]

Epstein, D. M. \& Altman, N. (1994) The 12 Stages of healing: a network approach to wholeness. New York: Allen.

Ferrer, J. (2002) Revisioning transpersonal theory: A participatory vision of human spirituality. New York: SUNY Press.

James, W. (1929) The varieties of religious experience: A study in human nature New York: Modern Library. (Original work published 1902).

Jung C. G. (1970) Man and his symbols. New York: Dell (Original work published 1964).

Jung, C. G. (1972a) Mandala symbolism. Princeton: Princeton University Press. 
Jung 1972b

Jung 2009

Jung 2009, 2013

Kandinsky 1977

Kellog 1978

Kelly 1993

Lemon, Gonnerman 2009

Lemon 2011

Levey, Levey 1998

Molesworth 1998

Palmer 2004

Picaso 1937

Profeta 2011

Rogers 1993

Rubin 2005

Rudhyar 1983

Smith 1990

Volkas 2014

Yoko Ono 1965
Jung, C. G. (1972b) The spirit in man, art, and literature. Princeton: Princeton University Press.

Jung, C. G. (2009) The Red Book. Liber Novus. New York: Norton. Jung, C. G. (2009, 2013). Images from The Red Book by Carl Jung. [Video file]. Retrieved from https://www.youtube.com/ watch? $\mathrm{v}=\mathrm{Xp8SQrBrQj8}$ [Viewed 10.01.2015]

Kandinsky, W. (1977[1912]) Concerning the spiritual in art. New York: Dover.

Kellog, J. (1978) Mandala. Path of beauty. Baltimore, Maryland: Mandala Assessment and Research Institute.

Kelly, S. (1993) Individuation and absolute: Hegel, Jung and the path toward wholeness. New York: Paulist Press.

Lemon, R. (Interviewee), \& Gonnerman, M. (Interviewer) (2009). The artist as researcher: An evening with Ralph Lemon: Art+ Invention Speaker Series Transcript and Video. [Interview transcript]. Retrieved from The Aurora Forum at Stanford University, 3 December, 2009, Web site: http://vimeo.com/ 9565798 [Viewed: 19.05.2014]

Lemon, R. (Interviewee), \& Bither, P. (Interviewer) (2010). A look at Ralph Lemon's How can you stay in the house all day and not go anywhere? Walker Art Center, September, 2010. [Video file]. Retrieved from http://www.youtube.com/watch?v=VErDqP3yvl4 [Viewed: 19.05.2014]

Lemon, R. (2011). Performance 14: On Line / Ralph Lemon, Jan. 26, $29 \& 30,2011$. [Video file]. Retrieved from http://www. youtube.com/watch?v=zD_0VrEV02s [Viewed: 19.05.2014]

Levey, J. \& Levey, M. (1998) Living in balance: A dynamic approach for creating harmony \& wholeness in a chaotic world. Berkeley: Conari Press.

Molesworth, H. (1998) Work avoidance: The everyday life of Marcel Duchamps's Readymades. Art Journal, 57/4, pp. 50-61.

Palmer, P. J. (2004) A hidden wholeness: The journey toward an undivided life. San Francisco: Jossey-Bass.

Picaso, P. (1937). Guernica. [Video file]. Retrieved from https:// www.youtube.com/watch?v=nf3Q7gS_YSA [Viewed: 12.05.2014]

Profeta, K. (2011) Ralph Lemon and the Buck Dance. Movement Research Performance Journal, 33, pp. 7-8.

Rogers, N. (1993) The creative connection: Expressive arts as healing. Palo Alto, CA: Science \& Behaviour Books.

Rubin, J. A. (2005) Artful therapy. New York: Wiley.

Rudhyar, D. (1983). Rhythm of wholeness: A total affirmation of being. Wheaton, Ill: Theosophical Publishing House.

Smith, C. D. (1990) Jung's quest for wholeness: A religious and historical perspective. New York: SUNY Press.

Volkas, A. (2014). Healing the wounds of history. [Internet resource]. Retrieved from http://www.healingthewoundsofhistory. org [Viewed: 09.06.2014]

Yoko Ono (1965). Cut Piece. [Video File]. Retrieved from https:// www.youtube.com/watch?v $=8$ Sc47KfJjcI [Viewed: 12.05.2014] 